\title{
Dietary chickpeas reverse visceral adiposity, dyslipidaemia and insulin resistance in rats induced by a chronic high-fat diet
}

\author{
Ying Yang ${ }^{1}$, Libin Zhou ${ }^{1}$, Yuanjun $\mathrm{Gu}^{2}$, Yibo Zhang ${ }^{1}$, Jingfeng Tang ${ }^{1}$, Fengying $\mathrm{Li}^{1}$, Wenbin Shang ${ }^{1}$, \\ Boren Jiang ${ }^{1}$, Xiaohua Yue $^{2}$ and Mingdao Chen ${ }^{1 *}$ \\ ${ }^{1}$ Shanghai Institute of Endocrine and Metabolic Diseases, Ruijin Hospital, School of Medicine, Shanghai Jiaotong University, \\ 197 Ruijin Road II, Shanghai 200025, China \\ ${ }^{2}$ Jumpsun Bio-medicine (Shanghai) Co. Ltd, Shanghai 201101, China
}

(Received 27 October 2006 - Revised 12 February 2007 - Accepted 21 March 2007)

The improved effects of dietary chickpeas on visceral adiposity, dyslipidaemia and insulin resistance were examined. Rats were fed a normal-fat diet (NFD), a high-fat diet (HFD) or a high-fat plus chickpea diet (HFD + CP) for 8 months. The epididymal fat pad weight $v$. total body weight of rats was higher in the HFD group (0.032 (SD 0.0042) g/g) than in the NFD group (0.015 (SD 0.0064) g/g) and smaller in the HFD + CP group $(0.023(\mathrm{SD} 0.0072) \mathrm{g} / \mathrm{g})$ compared with the HFD group $(P<0.05)$. Chickpea treatment also induced a favourable plasma lipid profile reflecting decreased TAG, LDL-cholesterol (LDL-C) and LDL-C:HDL-cholesterol levels $(P<0.05)$. HFD-fed rats had higher TAG concentration in muscle and liver, whereas the addition of chickpeas to the HFD drastically lowered TAG concentration (muscle, $39 \%$; liver, $23 \%$ ). The activities of lipoprotein lipase (LPL) in epididymal adipose tissue and hepatic TAG lipase in liver recorded a 40 and $23 \%$ increase respectively in HFD rats compared with those in NFD rats; dietary chickpeas completely normalised the levels. Furthermore, chickpea-treated obese rats also showed a markedly lower leptin and LPL mRNA content in epididymal adipose tissue. An insulin tolerance test, oral glucose tolerance test and insulinreleasing test showed that chickpeas significantly improved insulin resistance, and prevented postprandial hyperglycaemia and hyperinsulinaemia induced by the chronic HFD. The present findings provide a rational basis for the consumption of chickpeas as a functional food ingredient, which may be beneficial for correcting dyslipidaemia and preventing diabetes.

Chickpeas: Visceral adiposity: Dyslipidaemia: Insulin resistance

Obesity is the most common nutritional disorder in the developed world and is a strong risk factor for hypertension, hyperlipidaemia, CVD and type 2 diabetes mellitus, which are closely linked with insulin resistance, and collectively called the metabolic syndrome ${ }^{1}$. Obesity causes excess fat accumulation not only in adipocytes but also ectopically in tissues such as muscle, liver, $\beta$ cells and others, predisposing to the development of insulin resistance. Especially, skeletal muscle is a major site for insulin-stimulated glucose disposal ${ }^{2}$ and the accumulation of TAG within lipid droplets in skeletal muscle is positively correlated to the severity of insulin resistance ${ }^{3,4}$.

Recently, there has been growing interest in the use of medical plants and health foods for the treatment and prevention of disease $\mathrm{e}^{5,6}$. Therefore, studies on obesity and diabetes as lifestyle-related diseases have focused on the search of functional food ingredients that suppress the accumulation of body fat and improve lipid metabolism ${ }^{7-9}$, effects that, in turn, are beneficial for the amelioration of insulin resistance and prevention of type 2 diabetes.
The chickpea (Cicer arietinum L.) is one of the world's most important legume crops as it contains approximately $50 \%$ available carbohydrate, primarily in the form of starch, and $6.4 \%$ fat, of which most is unsaturated (for example, the fatty acids in the Kabuli-type seeds include $50 \cdot 3 \%$ oleic acid and $40 \%$ linoleic acid $)^{10}$. Moreover, the chickpea is considered to be a good source of protein ${ }^{11}$. In addition to culinary usage, the chickpea has been accepted as a natural Uighur traditional medicine in Xinjiang (China) for over 2500 years. As recorded in the pharmacopoeia ${ }^{12}$, the chickpea is effective in improving plasma lipid levels. Chickpeas may also be beneficial in the treatment of type 2 diabetes because it has a low glycaemic index, indicating that consuming an equi-available carbohydrate portion of chickpeas results in a lower postprandial blood glucose response than standard white wheatflour bread, through having higher levels of slowly digestible $\operatorname{starch}^{9,13,14}$.

However, the evidence for the use of chickpeas in insulin resistance and diabetes treatment is few and sometimes discrepant $^{15-18}$. The present study was carried out to further evaluate the effect of chickpeas on modifying lipids, reducing

Abbreviations: HDL-C, HDL-cholesterol; HFD, high-fat diet; HFD + CP, high-fat plus chickpea diet; HTGL, hepatic TAG lipase; ITT, insulin tolerance test; LDL-C, LDL-cholesterol; LPL, lipoprotein lipase; NFD, normal-fat diet.

* Corresponding author: Professor Mingdao Chen, fax + 8621 64673639, email mingdaochensh@yahoo.com 
visceral adiposity and aimed at identifying the potential use of chickpeas for the prevention and treatment of obesity, dyslipidaemia and diabetes.

\section{Materials and methods}

\section{Materials}

Chickpeas were obtained from Xinjiang Amina Agriculture Ltd (Xinjiang, China); rats and specific laboratory diets were purchased from SLAC Laboratory Animal Co. Ltd (Shanghai, China). Other chemicals, solvents and reagents were commercially available.

\section{Animals, diets, and experimental design}

Male Sprague-Dawley rats ( 8 weeks old, about $230 \mathrm{~g}$ body weight) were maintained in a temperature-controlled room $\left(22^{\circ} \mathrm{C}\right)$ on a $12 \mathrm{~h}$ light-dark cycle, and provided with a normal-fat diet (NFD) for 2 weeks after initiation of preliminary rearing; thereafter they were divided into different groups, with the groups matched for body weight. The animals had free access to water and the assigned diets for the different dietary formulations. Three kinds of diets were given in the experiments as follows: (1) a standard laboratory chow (NFD) containing $5 \mathrm{~g}$ fat, $22 \mathrm{~g}$ protein and $1381 \mathrm{~kJ} / 100 \mathrm{~g}$ diet; (2) a high-fat diet (HFD) created by mixing lard $(20 \%$, w/w), sugar $(4 \%$, w/w), wholemilk powder $(2 \%, \mathrm{w} / \mathrm{w})$ and cholesterol $(1 \%, \mathrm{w} / \mathrm{w})$ into the standard laboratory chow, which contained $25.71 \mathrm{~g}$ fat, $19.54 \mathrm{~g}$ protein and $1987 \mathrm{~kJ} / 100 \mathrm{~g}$ diet; (3) a high-fat plus chickpea diet (HFD + CP) was the same as the HFD diet, except that $10.0 \%$ of raw crushed chickpea seed replaced the standard laboratory chow, which contained $25.11 \mathrm{~g}$ fat, $19.36 \mathrm{~g}$ protein and $1965 \mathrm{~kJ} / 100 \mathrm{~g}$ diet. The experimental diets were freshly prepared once per month, and stored at $-20^{\circ} \mathrm{C}$ to avoid rancidity.

Rats ( $n$ 30) were randomly assigned to one of the following diets for 8 months: NFD, HFD or HFD + CP. Food intake was monitored over the course of $24 \mathrm{~h}$ for 7 consecutive days during the 8 -week dietary treatment period, and body weight was measured monthly. At 7 months of diet supplementation, an intraperitoneal insulin tolerance test (ITT; insulin at $2 \mathrm{U} / \mathrm{kg}$ ) and an oral glucose tolerance test (glucose at $2 \mathrm{~g} / \mathrm{kg}$ ) were performed respectively after an overnight fast, blood glucose levels measured from the tail vein were determined using a glucometer freestyle (in ITT) and the oxidase enzymic method (in the oral glucose tolerance test). At the end of the experiment ( 8 months after treatment), rats were deprived of food for $12 \mathrm{~h}$ and then killed by decapitation between 09.00 and 11.00 hours. The liver, muscle and adipose tissues were removed according to defined anatomical landmarks, the weights of the epididymal adipose tissues were measured, and then were immediately frozen using liquid $\mathrm{N}_{2}$ and kept at $-80^{\circ} \mathrm{C}$ until use. The serum was separated from blood samples and immediately stored at $-80^{\circ} \mathrm{C}$.

\section{Analytic methods}

Blood chemistry and hormone analysis. The serum TAG, total cholesterol, LDL-cholesterol (LDL-C), HDL-cholesterol
(HDL-C), alanine aminotransferase, blood urea N, creatinine and uric acid levels were measured using Beckman test kits (Beckman Coulter, Inc., Fullerton, CA, USA). Serum insulin and leptin levels were measured using commercial assay kits (rat insulin ELISA kit (Sibayagi, Gunma, Japan) and rat leptin RIA kit (Linco Research Inc., St Charles, MO, USA)).

\section{Measurement of tissue triacylglycerol content}

The rats' freeze-dried muscle was powdered, and cleaned of all visible connective tissue and blood under magnification. Lipid was extracted by a Folch extraction as previously described $^{19}$, the TAG was saponified in an ethanol-KOH solution at $60^{\circ} \mathrm{C}$, and glycerol content was determined fluorometrically.

Enzyme assays. The activity of lipoprotein lipase (LPL) in epididymal adipose tissue as well as hepatic TAG lipase (HTGL) in liver were analysed using a non-radioisotopic method according to the kit (Nanjing Jiancheng Bioengineering Institute, Nanjing, China), in accordance with the same principle as described previously ${ }^{20}$. Tissue samples were homogenised in $1 \mathrm{ml}$ of a solution containing $0.25 \mathrm{M}$-sucrose, 1 MM-EDTA, 10 MM-tri(hydroxymethyl)-aminomethane- $\mathrm{HCl}$ and $12 \mathrm{~mm}$-deoxycholate $(\mathrm{pH} 7 \cdot 4)$. The homogenates were centrifuged for $15 \mathrm{~min}$ at $3000 \mathrm{rpm}\left(4^{\circ} \mathrm{C}\right)$, after which the intermediate phase (between the floating fat droplets and the pellet) was extracted and then incubated under gentle agitation for $1 \mathrm{~h}$ at $37^{\circ} \mathrm{C}$ with a substrate mixture (supplied in the kit). A selective assay of each lipase was performed by addition of SDS and $\mathrm{NaCl}$ to inactivate HTGL and LPL, respectively. NEFA were measured by spectrophotometry using the complex cupric acetate-pyridine procedure. LPL and HTGL activity were expressed as microunits $(1 \mu \mathrm{U}=1 \mu \mathrm{mol}$ NEFA released per $\mathrm{h}$ incubation at $37^{\circ} \mathrm{C}$ ).

Extraction and Northern blot analysis of total RNA. 7 w>Epididymal adipose tissue total RNA was extracted using a TRIZOL reagent (Invitrogen Life Technologies Inc., Gaithersburg, MD, USA). The extracted RNA samples $(20 \mu \mathrm{g})$ were subjected to $1 \%$ agarose gel electrophoresis in the presence of formalin and then transferred onto a nylon membrane (Hybond-N; Amersham, Little Chalfont, Bucks, UK). Prehybridisation and hybridisation of the blots were performed as described previously ${ }^{21}$ using specific cDNA probes labelled with ${ }^{32} \mathrm{P}$ dCTP by random priming. The following primers were used: leptin, 5'-TCCCACCACAACGAAGTAC- $3^{\prime}$ and 5'-TCAGCCAGGGCATTATTTTC-3'; LPL, 5'-GCTTCACCCCATTCTGAGTT- $3^{\prime}$ and $5^{\prime}$-TCCAGGCTCTCTGGCTTCTG- $3^{\prime} ; \quad \beta$-actin, $5^{\prime}$-GCCAACCGTGAAAAGATGACC- $3^{\prime}$ and $5^{\prime}$-ATGCCACAGGATTCCATACCC- $3^{\prime}$. Autoradiograms were performed by exposure of radioactive membranes to a phosphoimager screen for $1-24 \mathrm{~h}$.

\section{Statistical analysis}

Statistical analyses were performed using SPSS 10.0 for Windows (SPSS Inc., Chicago, IL, USA). The results are presented as mean values and standard deviations. The statistical one-way ANOVA and $t$ test were used for statistical evaluation. 


\section{Results}

\section{Food intake}

In the HFD groups, food intake tended to be lower by about $15 \%$ than the NFD group in the first 2-week period that feed was changed from the NFD to the HFD; after the rats had adapted to the HFD, the food intake of the HFD rats was almost the same as the NFD group during the experimental period. As a result, rats in the two HF-fed groups consumed significantly more energy than rats in the NFD groups. Additionally, no significant difference was found in the food intake between the HFD (30.40 (SD 4.4) g/d per rat) and HFD + CP (31.39 (SD 6.2) g/d per rat) groups.

\section{Body and epididymal fat pad weights}

As indicated in Fig. 1(A), the body weight of the HFD group was significantly increased compared with the NFD group after 6 months of feeding $(P<0.05)$ and remained significantly increased for the duration of the experiment. Addition of chickpeas to the HFD reduced the weight gain, such that the HFD + CP group had a statistically significantly lower body weight $(P<0.05)$ from 6 months to the end of the experiment compared with the HFD group (NFD 584 (SD 31.2); HFD 654 (SD 45.2); HFD + CP 562 (SD 60.3) at 8 months).

The epididymal fat pad weight (an index of visceral adiposity in rats $\left.{ }^{22,23}\right) v$. total body weight of animals was significantly different among the three groups (Fig. 1(B)). It was higher in the HFD group $(0.032$ (SD 0.0042) g/g) than in
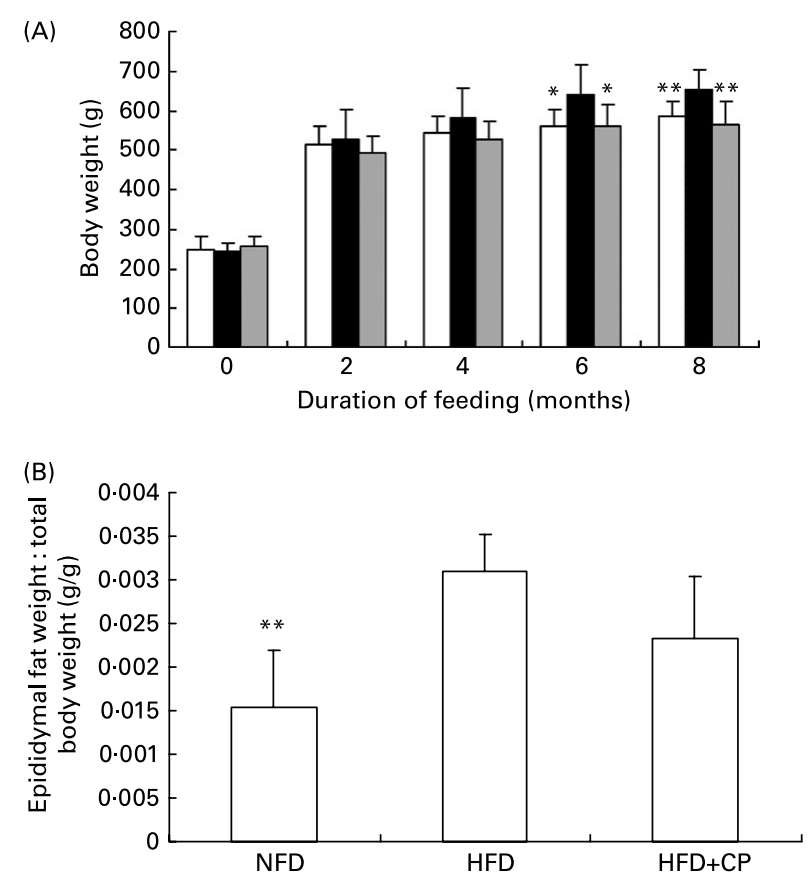

Fig. 1. Body-weight gain and epididymal fat pad weight of rats fed one of three diets for 8 months. (A) Body-weight changes throughout the experimental period for rats fed a normal-fat diet (NFD; $\square$ ), a high-fat diet (HFD; $\mathbf{\square})$ or the HFD plus chickpeas (HFD + CP; $\square$ ) for 8 months. (B) Epididymal fat pad weight:total body weight ratio after feeding with the NFD, HFD or HFD + CP for 8 months. Values are means, with standard deviations represented by vertical bars. Mean value was significantly different from that of the HFD group: ${ }^{\star} P<0.05,{ }^{\star \star} P<0.01$. both the NFD group (0.015 (SD 0.0064) g/g) and the HFD + CP group (0.023 (SD 0.0072) g/g; $P<0.05$ compared with the HFD group).

\section{Biochemical analysis for serum parameters}

As indicated in Table 1, serum TAG, LDL-C, leptin and LDL$\mathrm{C}: H D L-C$ levels were increased in the HFD rats, compared with those fed a standard diet. However, compared with the HFD group, chickpea treatment resulted in a $45 \%$ decrease in the serum TAG, a $23 \%$ decrease in LDL-C, a $35 \%$ rise in HDL-C and a $30 \%$ reduction in LDL-C:HDL-C. The serum leptin levels were also lower in the chickpea-fed group compared with the HFD group, but this did not reach significance. Unexpectedly, the HFD in the present experiment did not alter the serum level of total cholesterol.

On the other hand, the long-term HFD induced a slight increase of serum alanine aminotransferase levels and this tendency disappeared in rats treated with chickpeas, which suggested that chickpeas had some hepatic protective effect in this regard. The serum blood urea $\mathrm{N}$, creatinine and uric acid level showed no difference among the three groups.

\section{Lipoprotein lipase activities and triacylglycerol levels of tissues}

Rats fed the HFD had higher TAG concentration in muscle and liver tissue, whereas the addition of chickpeas drastically lowered TAG (muscle by $39 \%$ and liver by $23 \%$ ). The activities of LPL in epididymal fat and HTGL in liver increased by a 40 and $23 \%$ respectively in the HFD rats compared with NFD rats; however, dietary chickpeas completely normalised the levels (Table 2).

\section{Leptin and lipoprotein lipase mRNA expression}

Northern blot hybridisation of epididymal adipose tissue total RNA with cDNA probes for leptin and LPL mRNA is shown in Fig. 2. Long-term high-fat feeding induced the higher leptin and LPL mRNA expression, as reported in previous studies $^{24,25}$. However, chickpea-treated obese rats showed a markedly lower leptin and LPL mRNA content than untreated HFD groups.

\section{Insulin tolerance test and oral glucose tolerance test}

Basal plasma glucose levels showed no difference among the three groups after 7 months of diet supplementation. In response to insulin (ITT), plasma glucose levels at 60, 90 and $120 \mathrm{~min}$ in the HFD group were significantly higher than those in the NFD group $(P<0 \cdot 05)$. However, the HFD + CP group had a hypoglycaemic response compared with the HFD group, and no statistical differences were found between the NFD + CP group and NFD group at any time point (Fig. 3(A)). Furthermore, during the $120 \mathrm{~min}$ following glucose administration (Figs. 3(B) and (C)), plasma glucose levels in the HFD group were significantly higher than those in the control group at 60,90 and $120 \mathrm{~min}$, indicating that the rats in the HFD group had developed impaired glucose tolerance. However, in this test the responses recorded in the NFD + CP group did not reach those of the NFD 
Table 1. Biochemical analysis of serum parameters after the feeding period of 8 months (Mean values and standard deviations)

\begin{tabular}{|c|c|c|c|c|c|c|}
\hline \multirow[b]{2}{*}{ Parameter } & \multicolumn{2}{|c|}{ NFD group } & \multicolumn{2}{|c|}{ HFD group } & \multicolumn{2}{|c|}{ HFD + CP group } \\
\hline & Mean & SD & Mean & SD & Mean & SD \\
\hline TAG (mmol/l) & 1.08 & 0.31 & $2.05 \dagger$ & $1 \cdot 14$ & $1 \cdot 13^{\star}$ & 0.49 \\
\hline $\mathrm{TC}(\mathrm{mmol} / \mathrm{l})$ & 1.33 & 0.48 & 1.26 & 0.27 & 1.59 & 0.43 \\
\hline LDL-C (mmol/l) & 0.96 & 0.15 & $1.42 \dagger \dagger$ & 0.27 & $1.09^{*}$ & 0.11 \\
\hline $\mathrm{HDL}(\mathrm{mmol} / \mathrm{l})$ & 0.81 & 0.13 & $0.68 \dagger$ & 0.07 & $0.7^{\star \star}$ & 0.06 \\
\hline LDL-C:HDL-C & 1.21 & 0.21 & $2.05+\dagger$ & 0.46 & $1.43^{\star \star}$ & 0.24 \\
\hline Leptin ( $\mu \mathrm{g} / \mathrm{l})$ & $2 \cdot 13$ & 1.38 & 8.39†† & $3 \cdot 20$ & 6.96 & $2 \cdot 90$ \\
\hline ALT $(U / l)$ & $45 \cdot 00$ & 9.08 & $64.40 \dagger$ & $15 \cdot 00$ & $50 \cdot 60^{*}$ & 9.02 \\
\hline Blood urea N (mmol/l) & $5 \cdot 39$ & 0.94 & 5.40 & 0.77 & $5 \cdot 68$ & 1.11 \\
\hline Creatinine $(\mu \mathrm{mol} / \mathrm{l})$ & $50 \cdot 36$ & $6 \cdot 71$ & 55.90 & 6.90 & $56 \cdot 40$ & $4 \cdot 28$ \\
\hline Uric acid level $(\mu \mathrm{mol} / \mathrm{l})$ & $108 \cdot 91$ & 23.42 & $106 \cdot 40$ & 18.93 & $101 \cdot 80$ & 19.83 \\
\hline
\end{tabular}

NFD, normal-fat diet; HFD, high-fat diet; HFD + CP, high-fat plus chickpea diet; TC, total cholesterol; LDL-C,

LDL-cholesterol; HDL-C, HDL-cholesterol; ALT, alanine aminotransferase.

Mean value was significantly different from that of the HFD group: ${ }^{\star} P<0.05,{ }^{* \star} P<0.01$.

Mean value was significantly different from that of the NFD group: $\dagger P<0.05, \dagger \dagger P<0.01$.

controls, and increased responsiveness in the insulin-releasing test was even evident at the early phase of the experiment though it did not reach statistical significance. Nevertheless, postprandial levels of plasma glucose (90 and $120 \mathrm{~min})$ and insulin $(120 \mathrm{~min})$ in chickpea-treated rats were much lower than those in HFD-induced animals. Blood glucose was 6.68 (SD 1.02 ) $\mathrm{mmol} / \mathrm{l}$ in the HFD $+\mathrm{CP}$ group compared with $8.94(\mathrm{SD} 1.08) \mathrm{mmol} / \mathrm{l}$ in the HFD group $(P<0.01)$ and plasma insulin was $0 \cdot 18$ (SD 0.041) nmol/l in the HFD $+\mathrm{CP}$ group compared with 0.23 (SD 0.03 ) nmol/l in the HFD group $(P<0.05)$ at $120 \mathrm{~min}$. Therefore, the administration of chickpeas prevented postprandial hyperglycaemia and hyperinsulinaemia induced by a long-term HFD.

\section{Discussion}

Rats fed a HFD over an extended time became obese, dyslipaemic and insulin resistant - findings consistent with previous reports ${ }^{26,27}$. The present study focused on the possible beneficial effect of chickpeas to reverse visceral adiposity, hyperlipidaemia and impaired glucose tolerance in high-fatfed rats. In the present study increases in the body weight and weight of epididymal adipose tissues were successfully prevented by chickpea supplementation to HFD-fed rats. Furthermore, effects of dietary chickpeas on adipose tissue are not simply a reflection of decreased body weight because adipose decreases exceeded body-weight changes (Fig. 1). Chickpea treatment also resulted in the significant decrease of a number of pro-atherogenic factors, such as TAG, LDL-C and LDL-C:HDL-C. In addition, as adipocyte mRNA marker is closely related to adipose cell hypertrophy ${ }^{28,29}$, the lower expression of both LPL (the early differentiation marker) and leptin (the late differentiation marker ${ }^{29}$ ) in our experiments suggests a modulation of the adipocyte phenotye in the chickpea group.

Of the various body fat depots, the amount of visceral fat is positively correlated to the insulin sensitivity in animal models and man; insulin action is markedly impaired in individuals with visceral obesity ${ }^{30,31}$. Meanwhile, ectopic lipid deposition in muscle and liver is also postulated to mediate insulin resistance $^{32}$, with increased intramyocellular lipids contributing to the development of type 2 diabetes $^{33}$, and hepatic TAG content strongly associating with hepatic insulin resistance ${ }^{34}$. So, the hypolipidaemic and insulin-sensitising action of chickpeas in high-fat-fed rats may partly be due to the reduction of visceral and ectopic fat depots.

Similar favourable modifications in lipid profiles by chickpea feeding have been observed in several studies. Zulet et $a{ }^{18}{ }^{18}$ have showed that chickpea feeding significantly decreased serum total LDL-C and TAG levels and increased hepatic glucokinase activity in rats fed on a hypercholesterolaemic diet containing coconut oil and cholesterol ${ }^{18,35}$. Wang \& McIntosh ${ }^{6}$ have found a cholesterol-lowering ability of chickpeas, both processed by boiling and extrusion.

Table 2. Lipoprotein lipase (LPL) activities as well as triacylglycerol levels in tissues after chickpea administration for 8 months

(Mean values and standard deviations)

\begin{tabular}{|c|c|c|c|c|c|c|}
\hline \multirow[b]{2}{*}{ Parameter } & \multicolumn{2}{|c|}{ NFD group } & \multicolumn{2}{|c|}{ HFD group } & \multicolumn{2}{|c|}{ HFD + CP group } \\
\hline & Mean & SD & Mean & SD & Mean & SD \\
\hline Liver TAG $(\mu \mathrm{mol} / \mathrm{g})$ & 24.57 & $5 \cdot 64$ & $32 \cdot 18 \dagger$ & 6.58 & $24.74^{\star}$ & 7.03 \\
\hline Muscle TAG $(\mu \mathrm{mol} / \mathrm{g})$ & 3.41 & 1.84 & $6.92 \dagger$ & 1.63 & $4 \cdot 20^{*}$ & 1.58 \\
\hline Liver HTGL $(\mu \mathrm{U} / \mathrm{g})$ & 0.27 & 0.007 & $0.33+\dagger$ & 0.017 & $0.23^{\star \star}$ & 0.025 \\
\hline Adipose LPL $(\mu \mathrm{U} / \mathrm{g})$ & 1.60 & 0.41 & $2 \cdot 23 t$ & 0.44 & $1 \cdot 25^{\star \star}$ & 0.25 \\
\hline
\end{tabular}

NFD, normal-fat diet; HFD, high-fat diet; HFD + CP, high-fat plus chickpea diet; HTGL, hepatic TAG lipase. Mean value was significantly different from that of the HFD group: ${ }^{\star} P<0.05,{ }^{\star \star} P<0.01$.

Mean value was significantly different from that of the NFD group: $\uparrow P<0.05, \dagger \dagger P<0.01$. 
(A)
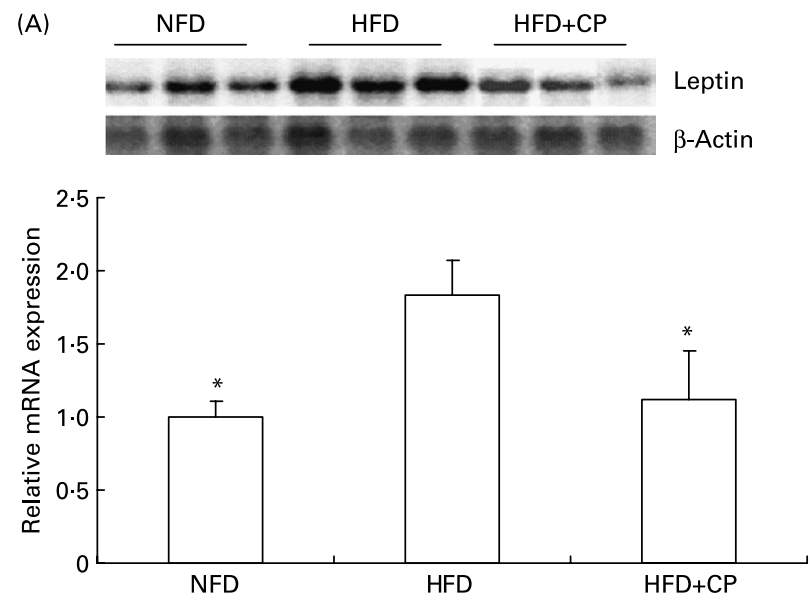

(B)
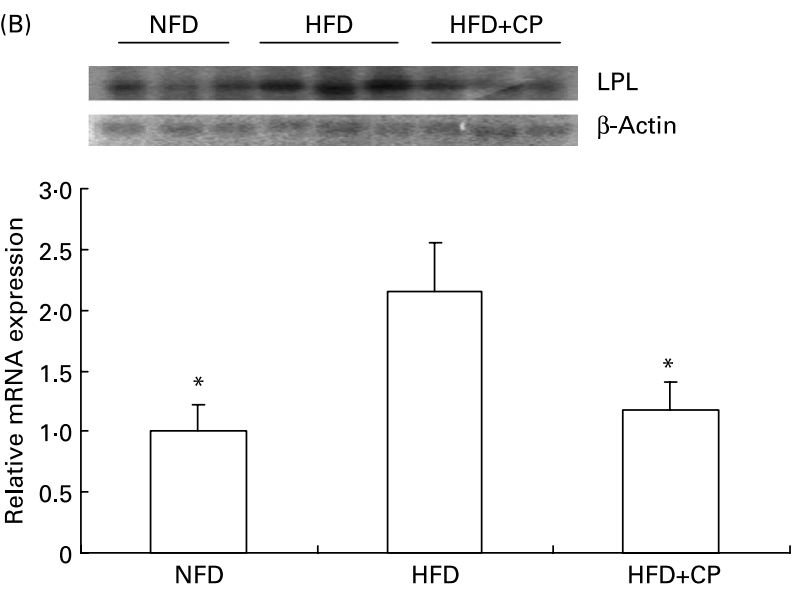

Fig. 2. Representative Northern blots for mRNA of (A) leptin and (B) lipoprotein lipase ( $L P L)$ in epididymal adipose tissue of rats that had been fed a normal-fat diet (NFD), a high-fat diet (HFD) or the HFD plus chickpeas (HFD $+\mathrm{CP})$ for 8 months. Total RNA (20 $\mu \mathrm{g}$ per lane) was analysed. The corresponding blot for the $\beta$-actin RNA is also shown. Values are means, with standard deviations represented by vertical bars. ${ }^{*}$ Mean value was significantly different from that of the HFD group $(P<0.05)$.

Others have also reported that dietary chickpeas successfully decreased TAG and cholesterol concentrations in the heart and liver tissue of rats $^{17,36}$.

Moreover, the present results are in agreement with previous work demonstrating that high-fat feeding increases LPL and HTGL activity in white adipose tissue and liver ${ }^{37}$. However, LPL and HTGL activities were found to be significantly reduced in HFD + CP rats; this might explain the lowered lipids in adipose tissue and liver in the HFD + CP group compared with the HFD group. In obese subjects, lowering of fat accumulation and reducing the circulating TAG levels are necessary in order to improve fat metabolism. Recently Naaz et $a l .{ }^{38}$ have shown that the soya isoflavone genistein decreases adipose deposition by decreasing LPL mRNA in female mice ${ }^{38}$. Lee also found that soya protein and genistein improved blood glucose, antioxidant enzyme activities, and lipid profile in streptozotocin-induced diabetic rats ${ }^{39}$. Therefore it is possible that some components of chickpea isoflavone may be responsible for the effects seen in the present study. In addition, the lipid fraction from chickpeas is high in unsaturated fatty acids, primarily linoleic and oleic acids,
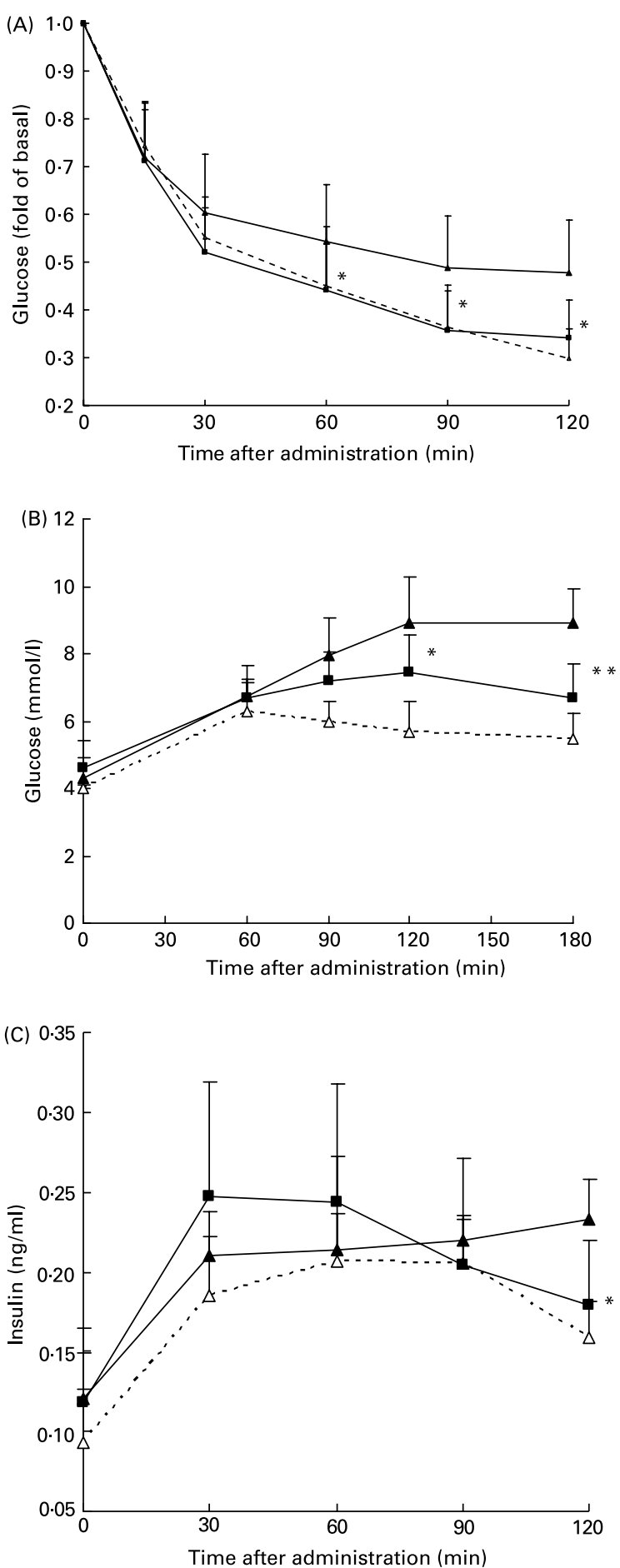

Fig. 3. Insulin resistance in rats fed a normal-fat diet (NFD; $\Delta$ ), a high-fat diet (HFD; $\Delta$ ) or the HFD plus chickpeas (HFD + CP; $\mathbf{\square})$. (A) Insulin tolerance test $(2 \mathrm{U} / \mathrm{kg}$ body weight; intraperitoneal) in rats fed the NFD, HFD or HFD + CP for 5 months. Changes in plasma glucose $(B)$ and insulin $(C)$ in rats during oral glucose tolerance tests $(2 \mathrm{~g} / \mathrm{kg}$ body weight) performed after 7 months on the different diets. Values are means, with standard deviations represented by vertical bars. Mean value of the HFD + CP group was significantly different from that of the HFD group: ${ }^{\star} P<0.05,{ }^{\star \star} P<0.01$.

which may have a synergistic effect of modifying body composition and plasma lipids.

Despite no statistically different basal plasma glucose levels among NFD, HFD and HFD + CP groups, the present results 
still indicate that chickpea-supplemented rats are protected from HFD-induced impairment of glucose tolerance and insulin resistance (Fig. 2). We hypothesise that the hypoglycaemic effect of chickpeas in the ITT and the oral glucose tolerance test were secondary to the metabolic changes associated with reduced adiposity. To the best of our knowledge, the present study is the first to demonstrate that dietary chickpeas improved insulin resistance (in the ITT) and reversed impaired glucose intolerance (in the oral glucose tolerance test) in longterm high-fat-fed animals. In healthy human subjects, both Johnson et al. ${ }^{16}$ and Nestel et al. ${ }^{15}$ found some hypoglycaemic effects after a single chickpea-based breakfast. However, no significant effects were obtained after a long-term (6 weeks) treatment according to Nestel et al. ${ }^{15}$; the lack of change could be due to the selection of normal subjects in this study ${ }^{15,16}$. Further research is necessary to demonstrate if chickpeas improve glucose disposal in insulin-resistant and diabetic subjects.

In conclusion, the results from the present study show that the chickpea has potential to assist with the prevention of excess fat accumulation induced by a chronic HFD and subsequently to prevent hyperlipidaemia as well as diabetes. The present findings provide a rational basis for the consumption of chickpeas as a functional food ingredient, which may be beneficial for correcting obesity-related diseases.

\section{Acknowledgements}

The present study was supported by the Shanghai-Unilever Research and Development Fund (2004) and a grant from the cultivation programme of Shanghai excellence young medical talent fund (2004). The present study was also partially supported by Jumpsun Bio-medicine (Shanghai) Co. Ltd. Y. Y. and L. Z. contributed equally to the present study.

\section{References}

1. Spiegelman BM \& Flier JS (2001) Obesity and the regulation of energy balance. Cell 104, 531-543.

2. Boden G, Lebed B, Schatz M, Homko C \& Lemieux S (2001) Effects of acute changes of plasma free fatty acids on intramyocellular fat content and insulin resistance in healthy subjects. Diabetes 50, 1612-1617.

3. Forouhi NG, Jenkinson G, Thomas EL, Mullick S, Mierisova S, Bhonsle U, McKeigue PM \& Bell JD (1999) Relation of triglyceride stores in skeletal muscle cells to central obesity and insulin sensitivity in European and South Asian men. Diabetologia 42, 932-935.

4. Krssak M, Falk Petersen K, Dresner A, DiPietro L, Vogel SM, Rothman DL, Roden M \& Shulman GI (1999) Intramyocellular lipid concentrations are correlated with insulin sensitivity in humans: a ${ }^{1} \mathrm{H}$ NMR spectroscopy study. Diabetologia 42, $113-116$.

5. Crespy V \& Williamson G (2004) A review of the health effects of green tea catechins in in vivo animal models. J Nutr 134, Suppl. 12, 3431S-3440S.

6. Wang YH \& McIntosh GH (1996) Extrusion and boiling improve rat body weight gain and plasma cholesterol lowering ability of peas and chickpeas. J Nutr 126, 3054-3062.

7. Torres N, Torre-Villalvazo I \& Tovar AR (2006) Regulation of lipid metabolism by soy protein and its implication in diseases mediated by lipid disorders. J Nutr Biochem 17, 365-373.
8. Bhattacharya A, Rahman MM, Sun D, Lawrence R, Mejia W, McCarter R, O'Shea M \& Fernandes G (2005) The combination of dietary conjugated linoleic acid and treadmill exercise lowers gain in body fat mass and enhances lean body mass in high fat-fed male Balb/C mice. J Nutr 135, 1124-1130.

9. Leterme $\mathrm{P}$ (2002) Recommendations by health organizations for pulse consumption. Br J Nutr 88, Suppl. 3, S239-S242.

10. Thorne MJ, Thompson LU \& Jenkins DJ (1983) Factors affecting starch digestibility and the glycemic response with special reference to legumes. Am J Clin Nutr 38, 481-488.

11. Khan MA, Akhtar N, Ullah I \& Jaffery S (1995) Nutritional evaluation of desi and kabuli chickpeas and their products commonly consumed in Pakistan. Int J Food Sci Nutr 46, 215-223.

12. Committee of Chinese Pharmacopoeia (1998) Chinese pharmacopoeia commission of sanitary ministry of People's Republic of China. Chinese Pharmacopoeia. In Uigur Pharmacopoeia Fascicule. Xinjiang, China: Xinjiang Science and Technology Sanitation Publisher.

13. Hawkins A \& Johnson SK (2005) In vitro carbohydrate digestibility of whole-chickpea and chickpea bread products. Int $J$ Food Sci Nutr 56, 147-155.

14. Foster-Powell K, Holt SH \& Brand-Miller JC (2002) International table of glycemic index and glycemic load values. Am J Clin Nutr 76, 55-56.

15. Nestel P, Cehun M \& Chronopoulos A (2004) Effects of longterm consumption and single meals of chickpeas on plasma glucose, insulin, and triacylglycerol concentrations. Am J Clin Nutr 79, 390-395.

16. Johnson SK, Thomas SJ \& Hall RS (2005) Palatability and glucose, insulin and satiety responses of chickpea flour and extruded chickpea flour bread eaten as part of a breakfast. Eur $J$ Clin Nutr 59, 169-176.

17. Habib K \& Ahsan A (2004) Comparative serum cholesterol and glucose responses of rats fed on wheat flour and chickpea composite flour. Asia Pac J Clin Nutr 13, S66.

18. Zulet MA, Macarulla MT, Portillo MP, Noel-Suberville C, Higueret P \& Martinez JA (1999) Lipid and glucose utilization in hypercholesterolemic rats fed a diet containing heated chickpea (Cicer aretinum L.): a potential functional food. Int J Vitam Nutr Res 69, 403-411.

19. Frayn KN \& Maycock PF (1980) Skeletal muscle triacylglycerol in the rat: methods for sampling and measurement, and studies of biological variability. J Lipid Res 21, 139-144.

20. Nozaki S, Kubo M, Matsuzawa Y \& Tarui S (1984) Sensitive non-radioisotopic method for measuring lipoprotein lipase and hepatic triglyceride lipase in post-heparin plasma. Clin Chem 30, 748-751.

21. Neschen S, Moore I, Regittnig W, Yu CL, Wang Y, Pypaert M, Petersen KF \& Shulman GI (2002) Contrasting effects of fish oil and safflower oil on hepatic peroxisomal and tissue lipid content. Am J Physiol Endocrinol Metab 282, E395-E401.

22. Brand-Miller JC, Holt SH, Pawlak DB \& McMillan J (2002) Glycemic index and obesity. Am J Clin Nutr 76, 281S-285S.

23. Yajima H, Noguchi T, Ikeshima E, Shiraki M, Kanaya T, Tsuboyama-Kasaoka N, Ezaki O, Oikawa S \& Kondo K (2005) Prevention of diet-induced obesity by dietary isomerized hop extract containing isohumulones, in rodents. Int $J$ Obes (Lond) 29, 991-997.

24. Zabala A, Churruca I, Fernandez-Quintela A, Rodriguez VM, Macarulla MT, Martinez JA \& Portillo MP (2006) trans10,cis-12 Conjugated linoleic acid inhibits lipoprotein lipase but increases the activity of lipogenic enzymes in adipose tissue from hamsters fed an atherogenic diet. Br J Nutr 95, 1112-1119.

25. Takahashi $\mathrm{Y} \&$ Ide $\mathrm{T}$ (2000) Dietary $n-3$ fatty acids affect mRNA level of brown adipose tissue uncoupling protein 1 , 
and white adipose tissue leptin and glucose transporter 4 in the rat. Br J Nutr 84, 175-184.

26. Tsutsumi K, Inoue Y, Shima A, Iwasaki K, Kawamura M \& Murase T (1993) The novel compound NO-1886 increases lipoprotein lipase activity with resulting elevation of high density lipoprotein cholesterol, and long-term administration inhibits atherogenesis in the coronary arteries of rats with experimental atherosclerosis. J Clin Invest 92, 411-417.

27. Kishino E, Ito T, Fujita K \& Kiuchi Y (2006) A mixture of the Salacia reticulata (Kotala himbutu) aqueous extract and cyclodextrin reduces the accumulation of visceral fat mass in mice and rats with high-fat diet-induced obesity. J Nutr 136, 433-439.

28. Raclot T, Groscolas R, Langin D \& Ferre P (1997) Site-specific regulation of gene expression by $n-3$ polyunsaturated fatty acids in rat white adipose tissues. J Lipid Res 38, 1963-1972.

29. Ailhaud G, Grimaldi P \& Negrel R (1992) Cellular and molecular aspects of adipose tissue development. Аппи Rev Nutr 12, 207-233.

30. Axen KV, Dikeakos A \& Sclafani A (2003) High dietary fat promotes syndrome $\mathrm{X}$ in nonobese rats. J Nutr 133, 2244-2249.

31. Carey DG, Jenkins AB, Campbell LV, Freund J \& Chisholm DJ (1996) Abdominal fat and insulin resistance in normal and overweight women: direct measurements reveal a strong relationship in subjects at both low and high risk of NIDDM. Diabetes 45, $633-638$.
32. McGarry JD (2002) Banting lecture 2001, dysregulation of fatty acid metabolism in the etiology of type 2 diabetes. Diabetes 51, $7-18$.

33. Kelley DE, Goodpaster BH \& Storlien L (2002) Muscle triglyceride and insulin resistance. Annu Rev Nutr 22, 325-346.

34. Utzschneider KM \& Kahn SE (2006) Review: the role of insulin resistance in nonalcoholic fatty liver disease. J Clin Endocrinol Metab 91, 4753-4761.

35. Zulet MA \& Martinez JA (1995) Corrective role of chickpea intake on a dietary-induced model of hypercholesterolemia. Plant Foods Hum Nutr 48, 269-277.

36. Muzaffar M, Bakhsh R, Khan S \& Khan S (1989) Effect of different dietary brans on lipid metabolism in male albino rats. Nahrung 33, 167-170.

37. Ait Yahia D, Madani S, Prost J, Bouchenak M \& Belleville J (2005) Fish protein improves blood pressure but alters HDL2 and HDL3 composition and tissue lipoprotein lipase activities in spontaneously hypertensive rats. Eur J Nutr 44, 10-17.

38. Naaz A, Yellayi S, Zakroczymski MA, Bunick D, Doerge DR, Lubahn DB, Helferich WG \& Cooke PS (2003) The soy isoflavone genistein decreases adipose deposition in mice. Endocrinology 144, 3315-3320.

39. Lee JS (2006) Effects of soy protein and genistein on blood glucose, antioxidant enzyme activities, and lipid profile in streptozotocin-induced diabetic rats. Life Sci 79, 1578-1584. 